\title{
Lidil
}

Revue de linguistique et de didactique des langues

$61 \mid 2020$

Le mépris en discours

Philippe Moser et Bruno Moretti (dir.), La situation sociolinguistique en Suisse, Cahiers internationaux de sociolinguistique, $\mathrm{n}^{\circ} 14$

Paris, L'Harmattan, 2018-2019, 206 p.

Lan Wang

CpenEdition

Journals

Édition électronique

URL : http://journals.openedition.org/lidil/7621

DOI : $10.4000 /$ lidil.7621

ISSN : $1960-6052$

Éditeur

UGA Éditions/Université Grenoble Alpes

Édition imprimée

ISBN : 978-2-37747-195-9

ISSN : $1146-6480$

Référence électronique

Lan Wang, «Philippe Moser et Bruno Moretti (dir.), La situation sociolinguistique en Suisse, Cahiers

internationaux de sociolinguistique, nº 14 », Lidil [En ligne], 61 | 2020, mis en ligne le 02 mai 2020,

consulté le 24 septembre 2020. URL : http://journals.openedition.org/lidil/7621 ; DOI : https://doi.org/ 10.4000/lidil.7621

Ce document a été généré automatiquement le 24 septembre 2020.

(C) Lidil 


\section{Philippe Moser et Bruno Moretti (dir.), La situation sociolinguistique en Suisse, Cahiers internationaux de sociolinguistique, $\mathrm{n}^{\circ} 14$}

Paris, L'Harmattan, 2018-2019, 206 p. Lan Wang

\section{RÉFÉRENCE}

Philippe Moser et Bruno Moretti (dir.), La situation sociolinguistique en Suisse, Cahiers internationaux de sociolinguistique, $\mathrm{n}^{\circ}$ 14, Paris, L'Harmattan, 2018-2019, 206 p.

1 Le numéro 14 des Cahiers internationaux de sociolinguistique, sous la direction de Philippe Moser et de Bruno Moretti (Istituto di Lingua e Letteratura italiana, Université de Berne) présente des recherches récentes sur la situation sociolinguistique dynamique de la Suisse, terrain très connu pour son plurilinguisme. La Confédération reconnait quatre langues nationales (allemand, français, italien et romanche) et sauvegarde leur distribution dans les quatre communautés linguistiques traditionnelles par respect du «principe de territorialité». Cependant, la diversité sociolinguistique de ce pays européen ne s'arrête pas à quatre langues nationales. La présence de langues populaires cantonales, de langues de migration et de l'anglais stimule de nouvelles formes de contacts plurilingues dans la société.

Ce numéro est divisé en six chapitres. Dans le premier, Iwar Werlen travaille sur les rapports entre l'allemand standard et les variétés du suisse allemand (Schweizerdeutsch) en Suisse alémanique : la diglossie (Fergueson, 1959), la diglossie médiale (Kolde, 1981), la langue de proximité et la langue de distance (Christen, 2004), ainsi que le bilinguisme si l'on considère ces langues comme différentes (Werlen, 1999). À partir de 1950, suite à des changements importants dus à la migration, à l'évolution 
du monde du travail et des médias, les jeunes commencent à utiliser des formes langagières hybrides dans leur communication et un modèle dynamique du dialecte moderne se forme. Dans le chapitre 2, Mathieu Avanzi se sert des méthodes des sciences participatives pour cartographier les différences lexicales, grammaticales et phonétiques des usages entre le français de la Suisse romande et de la France voisine. Par exemple, du côté de la frontière suisse, les régionalismes francoprovençaux et jurassiens sont plus vivaces que du côté français de la frontière. Mais tant en Suisse romande qu'en France, les variantes du français de référence font preuve de plus de vitalité que les variantes populaires ou régionales.

La contribution de Bruno Moretti, Matteo Casoni et Elena Maria Pandolfi porte essentiellement sur les différentes situations de l'italien dans les cantons du Tessin et des Grisons ainsi que la standardisation de l'italien suisse. On observe une réduction progressive de la dialectophonie au Tessin, et une conservation du dialecte dans les Grisons. À la différence du standard italien dont les règles sont codifiées dans les grammaires et les dictionnaires, la standardisation de l'italien suisse est un processus de "standard by mere usage» (Ammon, 2003, p. 2). Le chapitre de Matthias Grünert présente la situation du romanche, langue nationale la moins répandue en Suisse. On peut y voir les efforts remarquables juridiques, administratifs, institutionnels et médiatiques des locuteurs ayant pour objectif de sauvegarder et de promouvoir cette langue minoritaire. À la suite de la présentation des situations complexes des quatre langues nationales, Sabine Christopher essaie de répondre à la question tant didactique que politique «quelles langues l'école enseigne-t-elle en Suisse?» et ce volume se termine par une contribution de Philippe Blanchet intitulée "Quelques enseignements tirés de la situation sociolinguistique en Suisse ». Il s'agit d'une " vue d'extérieur » sur l'ensemble de ces études.

De plus, quelques notions théoriques méritent notre attention dans ce numéro. Par exemple, le concept de dilalie (Berruto, 1987) qui est employé dans le chapitre 3 pour décrire les fonctions communicatives déséquilibrées entre l'italien et le dialecte : l'italien couvre l'ensemble des fonctions communicatives tandis que le dialecte remplit seulement une fonction communicative réduite au sein de la famille et dans certains contextes de travail. En situation de dilalie, il existe un chevauchement fonctionnel entre deux variétés d'une langue. Il parait également nécessaire de noter la pluricentricité des langues (Clyne, 1989), les modèles de standardisation des langues pluricentriques (Ammon, 1989) et la représentation en cônes d'une langue bicentrique, exemple de l'italien d'Italie et de l'italien de Suisse. Il s'agit d'outils théoriques intéressants pour analyser les rapports entre variétés standard et non standard des langues pluricentriques comme le français, l'anglais, l'allemand, le chinois, etc.

Ce numéro a également d'autres qualités : un style facilitant l'accessibilité au sens et un traitement scientifique solide à partir de riches données qualitatives et quantitatives. Il offre non seulement des informations complètes sur la situation sociolinguistique en Suisse, mais apporte aussi des découvertes théoriques et méthodologiques pour les futures recherches en terrain multilingue. 


\section{AUTEURS}

\section{LAN WANG}

LIDILEM (EA 609), Université Grenoble Alpes 